\title{
Nós e os outros: as migrações no Portugal contemporâneo
}

\section{Pedro Góis}

Faculdade de Economia

da Universidade de Coimbra e

Centro de Estudos Sociais

-pedro.gois@uc.pt

Dol https://doi.org/10.34913/

journals/lingualugar.2020.e417 
Há 50 anos Portugal era um país de emigração que tinha alguns imigrantes. Após o anunciado fim da emigração constatamos que atravessámos vários ciclos de emigração e retorno, mas que nunca os fluxos de saída deixaram de ter consequências sociais e sociológicas. Afinal a emigração é mais estrutural do que pensáramos. Hoje é um país de migrações. Entre o retorno ou repatriamento de muitos nacionais portugueses e o acolhimento de centenas de milhares de estrangeiros a demografia nacional ganhou diversidade e complexidade. Sem a imigração seríamos menos, mais pobres e mais velhos. A dinâmica e diversidade das origens dos migrantes para Portugal, mas, também, a geografia múltipla dos destinos dos emigrantes portugueses representa um sinal de alteração do posicionamento do país no sistema migratório global. Numa tradicional lógica evolucionista, Portugal (ainda) não é um centro, mas (já) não é periferia (ou talvez o seja para alguns migrantes). Numa nova lógica de sistemas paralelos talvez as migrações portuguesas possam coexistir num país de emigração e de imigração. Sinal claro deste estatuto é, por exemplo, o facto da lei de nacionalidade ter evoluído, ao sabor de ideologias mais ou menos inclusivas e alargado o número de cidadãos que hoje fazem parte da comunidade nacional. Somos mais do que a soma dos que vivem em Portugal com os que dele partiram. Uma sociedade em movimento, aberta, plena de dinâmicas migratórias que permite antever um futuro cheio de desafios de integração e de gestão da diversidade. Uma sociedade dialogante com o mundo e em interação constante é, seguramente, uma sociedade em crescimento.

Palavras-chave: Emigração; imigração; neo-semi-periferia; "comunidade nacional inclusiva"; nação-plural. 
Il y a 50 ans, le Portugal était un pays d'émigration qui ne comptait que quelques migrants. Après la soi-disant fin de l'émigration, il y a une trentaine d'années, on en éprouve encore les conséquences sociales et sociologiques. Après tout, la migration est plus structurelle qu'on ne l'a cru. Aujourd'hui, le Portugal est un pays de migrations, au pluriel. Entre le retour ou le rapatriement de nombreux Portugais et l'accueil de centaines de milliers d'étrangers, la démographie nationale a gagné en diversité et en complexité. Sans immigration, nous serions moins nombreux, plus pauvres et plus vieux. La dynamique et la diversité des origines des migrants au Portugal, mais aussi la géographie des destinations des émigrés portugais représente un signe d'un changement dans la position du pays dans le système migratoire mondial. Dans une logique évolutive traditionnelle, le Portugal n'est pas (encore) un centre, mais n'est pas (ou n'est plus) une périphérie. Dans une nouvelle logique de systèmes parallèles, peut-être, les migrations portugaises pourront coexister dans un pays de migration et d'immigration. Un signe clair de ce statut est, par exemple, le fait que la loi sur la nationalité a évolué pour devenir vraiment inclusive et progressiste. Nous, les Portugais, sommes une communauté imaginée représentant beaucoup plus que la somme de ceux qui vivent au Portugal et de ceux qui en sont partis. Une société en mouvement, ouverte, pleine de dynamiques migratoires, qui permet toujours un avenir plein de défis d'intégration et de gestion de la diversité. Une société en dialogue avec le monde et en interaction permanente avec lui.

Mots-clefs: Émigration; immigration; néo-semi-périphérie; "communauté nationale inclusive»; nation plurielle.

Os fluxos migratórios, internos ou internacionais, são uma das principais forças de transformação social em todo o mundo capazes de engrandecer diversas questões de ordem económica, jurídica, política, social ou cultural (Baganha, Marques e Góis, 2010; Castles, 2005). Também em Portugal, vistas retrospetivamente, é possível afirmar que as migrações ajudaram a construir o país tal como o conhecemos hoje. Na verdade, é virtualmente impossível pensar um Portugal contemporâneo sem abordar, em conjunto, a emigração e a imigração e a forma como estas dimensões demográficas e sociológicas moldaram a sociedade portuguesa ao longo do último século (Góis e Marques, 2018). Se hoje somos uma sociedade diversa e feita de culturas múltiplas, devemos às migrações muita dessa variedade. 
No decurso das últimas décadas, Portugal, a exemplo de outros países da Europa do Sul, designadamente a Espanha, a Itália ou a Grécia, vem realizando uma transição de uma variável demográfica fundamental: as migrações, num percurso de tradicional "país de emigração" a "país de imigração" (Esteves, 1991; Baganha, 1996). Embora os indicadores demográficos não sejam permanentes nem definitivos parece claro que a atratividade do país para migrantes estrangeiros tem sido coerente e estável ao longo das últimas três décadas, isto é, pelo menos desde o final dos anos 80 do século XX.

A transição entre emigração e imigração, porém, não ocorreu de forma brusca ou definitiva, sendo percetível através da evolução de múltiplos indicadores que não apenas indicadores demográficos. Por exemplo, a dependência das remessas financeiras dos emigrantes, típica dos anos 60 e 70, foi ultrapassada por novas formas de remessas, como as da União Europeia (UE), o Investimento Direto Estrangeiro (IDE) ou as exportações de bens transacionáveis, sem que as remessas tenham deixado de representar um peso importante na economia, mormente na economia regional ou local (Mateus, 2013; Silva, 2006). Entre os anos 80 do século passado e a atualidade as remessas financeiras permaneceram elevadas e importantes em termos absolutos, mas, de certa forma, perderam a sua importância relativa na economia nacional (Ferreira, Lahr, Ramos e Castro, 2020).

Para os autores que trabalharam, à época, estas questões, Portugal era, no final dos anos 1990, um autodefinido "país de imigração" imaginando-se a si próprio como um país que realizara a transição entre a emigração (que caraterizava um estado de subdesenvolvimento estrutural) e um país de imigração, um país do centro que abandonava a periferia e se tornava central (Baganha, 1991; 1992). Embora esta transição não tenha sido inteiramente realizada, por motivos que explicaremos adiante, é aceite de forma consensual que Portugal se encontra, ao longo dos últimos 30 anos, num momento de transformação quanto à sua posição no sistema migratório global (de Haas et al., 2019; Haas, Miller e Castles, 2020).

Neste contexto, Portugal foi sendo, ao longo das últimas décadas, encarado e/ou conceptualizado de diversas formas por diferentes autores: como espaço de transição, espaço de circulação ou plataforma de redistribuição de diferentes fluxos migratórios, como semiperiferia no sistema migratório global, como país de desenvolvimento médio numa rota de passagem entre origem e destinos diversos; como porta de entrada na UE para imigrantes de países terceiros (Góis e Marques, 2018). 
Complementarmente, Portugal tem sido destino final de diversos fluxos migratórios, alguns já tradicionais (como os imigrantes dos países africanos de língua oficial portuguesa [PALOP], Índia ou China), outros mais recentes como os imigrantes magrebinos, paquistaneses, nepaleses ou do Leste da Europa (ex. Rússia, Moldávia ou Ucrânia) (Baganha, Marques e Góis, 2005). Simultaneamente, subsiste um Portugal de emigração que, baseado numa história migratória centenária, se reconstrói geração após geração encontrando fora do país espaço para uma empregabilidade, para uma carreira profissional ou, simplesmente, para uma fuga à pobreza que o país não sabe enquadrar (Peixoto et al., 2019).

Nos últimos 50 anos Portugal assistiu:

i) a diferentes ciclos de emigração e retorno;

ii) ao repatriamento dos portugueses residentes nas ex-colónias;

iii) a uma migração de refugiados da guerra colonial;

iv) a diferentes ciclos e tipos de imigração laboral (de trabalhadores qualificados e de trabalhadores indiferenciados), de reagrupamento familiar e de inativos (estudantes ou reformados).

Uma análise histórica da evolução destes fluxos migratórios ajuda-nos a compreender esta realidade e a caraterizar a forma como as migrações em Portugal moldaram a sociedade portuguesa. Comecemos por enunciar a dimensão emigratória portuguesa.

\section{Nós e os outros. Os últimos 50 anos de migrações portuguesas na Europa}

A história contemporânea portuguesa é marcada por dois grandes ciclos migratórios: o ciclo transatlântico e o ciclo intraeuropeu. $O$ ciclo transatlântico desenvolveu-se ao longo do século XIX, atingiu o seu apogeu na viragem do século XIX-XX e, no que concerne à emissão massiva de emigrantes, entrou em declínio no período entre as duas grandes guerras. Estima-se que durante este primeiro ciclo mais de cinquenta milhões de europeus, dos quais aproximadamente dois milhões de portugueses, tenham abandonado os seus países de origem para se fixarem nas Américas. As causas para a decadência deste ciclo migratório são múltiplas. Destacamos, o recrudescimento dos sentimentos nacionalistas nos Estados Unidos, nomeadamente no início do século XX, e a eclosão e desenvolvimento da Grande Depressão de 1929. Estes eventos concertados levaram à implementação de políticas antimigratórias nos principais países de imigração do Continente Americano, que irão pôr fim ao ciclo das Grandes Migrações Transatlânticas (Baganha, 1990) e abrir espaço para o posterior desenvolvimento de um ciclo migratório europeu. 


\section{Migrações após 1945}

A necessidade de reconstruir uma Europa devastada pela guerra criou, no entretanto, novas possibilidades, dando início ao segundo grande ciclo migratório europeu, cuja primeira vaga perdurará até à crise petrolífera de meados dos anos 70 e cuja principal característica foi a sua dimensão intraeuropeia. Também aqui há causas diversas. Durante este segundo ciclo migratório o mercado de trabalho dos países europeus industrializados segmentou-se, sendo a procura no mercado secundário progressivamente satisfeita por mão-de-obra estrangeira originária na sua esmagadora maioria dos países da Europa do Sul. As políticas restritivas de imigração implementadas na sequência da crise petrolífera de 1973-74 e da recessão económica que se lhe seguiu, marcam o início de uma nova fase nos processos migratórios europeus, mas, até àquela data, as políticas de imigração podem caracterizar-se como políticas de "porta aberta" (Devoto e González-Bernaldo, 2001).

Durante a fase de crescimento sustentado do pós-guerra, a Europa industrializada levou a cabo uma política de recrutamento de trabalhadores estrangeiros. Incentivou a vinda de vários milhões de imigrantes e de seus familiares cuja fixação foi facilitada pelas necessidades de mão-de-obra existentes, pelas possibilidades de mobilidade económica e social que daí advinham para os nacionais, bem como e sobretudo, pela convicção generalizada de que esta situação era temporária e poderia ser facilmente invertida, uma vez resolvidos os desequilíbrios conjunturais do mercado de trabalho, ou logo que os imigrantes, amealhadas as poupanças necessárias ou confrontados com situações de desemprego, retornassem aos seus países de origem. A ideia da temporalidade das migrações era defendida como a solução para necessidades conjunturais de mão-de-obra e o sistema, sob o título de trabalhadores convidados, continha em si uma ideia nacionalista de mercado de trabalho (King, 1995).

Portugal, só se encontra substancialmente envolvido no ciclo migratório intraeuropeu a partir da década de 60 do século $X X$ e, mais concretamente, após a celebração dos acordos bilaterais entre $\mathrm{O}$ governo de Salazar e alguns governos europeus para fornecimento de mão-de-obra nacional, que ocorreram com a França (em 1963), com a Holanda (em 1963) e com a República Federal da Alemanha (em 1964). A emigração para França de trabalhadores do Sul da Europa é um bom exemplo das similitudes e diferenças (ou até de complementaridade) que caracterizam os emigrantes destes países. Entre 1950 e 1959 os emigrantes italianos representavam mais de metade do total de afluxo de 
mão-de-obra estrangeira. Em 1960, o número de entrada de espanhóis em França estava já equiparado ao número de italianos, contribuindo cada uma destas nações com 30 mil migrantes num total de 73 mil entradas. Entre 1961 e 1965 os espanhóis substituíram os italianos como principal mão-de-obra estrangeira em França. Nos anos seguintes, de 1966 a 1972, Portugal substituiu a Espanha, como o principal fornecedor de mão-de-obra imigrante à França. Esta contribuição foi particularmente significativa nos anos de 1970 e 1971 em França (Antunes, 1970; 1973). Num total de 255 mil imigrantes em 1970 e de 218 mil em 1971, Portugal contribuiu com $53 \%$ (136 mil) e 51\% (111 mil migrantes) respetivamente (Góis e Marques, 2018).

Um outro facto importante tem a ver com a relevância da componente de emigração clandestina, as saídas do país de forma oculta e não declarada no total da emigração. O número de saídas totais (isto é, incluindo as estimativas feitas para saídas de clandestinos) entre 1931-1974 foi sensivelmente de dois milhões de partidas. A média anual de partidas legais foi de 31 mil emigrantes e a média anual de partidas clandestinas de 14 mil emigrantes. A distribuição das saídas de clandestinos foi, contudo, particularmente assimétrica uma vez que mais de três quartos dessas partidas ocorreu entre 1964 e 1973 refletindo as alterações sociopolíticas em Portugal com o desenvolvimento da guerra colonial e da imposição de um serviço militar obrigatório (SMO) para todos os jovens do sexo masculino maiores de idade. A fuga a este SMO foi feita, para muitos destes jovens, através da estratégia migratória tendo sido França o destino principal. Votar com os pés foi, também neste caso, uma realidade sociológica bem destacada.

Como se pode ver pela análise do Quadro 1 [ver página seguinte] a opção pela Europa ganha alguma relevância a partir de 1957 e torna-se dominante para a maior parte dos emigrantes portugueses a partir de 1962.

Desde o final dos anos 50 até 1974 a atração exercida pela França e, em menor grau, pela Alemanha, domina completamente a emigração portuguesa. Assim, do milhão e quatrocentas mil saídas verificadas entre 1962 e 1974, 75\% dirigiram-se para estes dois países, respetivamente $62 \%$ para a França e $13 \%$ para a Alemanha. Esta viragem para as migrações intraeuropeias não mais abandonou a história da emigração portuguesa. 


\begin{tabular}{|c|c|c|c|c|c|c|c|c|c|c|}
\hline 1950 & 14.143 & 938 & & 21.491 & 319 & 1 & 81 & 401 & 21.892 & $1.83 \%$ \\
\hline 1951 & 28.104 & 676 & & 33.341 & 418 & 2 & 254 & 674 & 34.015 & $1.98 \%$ \\
\hline 1952 & 41.518 & 582 & & 46.544 & 650 & 4 & 209 & 863 & 47.407 & $1.82 \%$ \\
\hline 1953 & 32.159 & 1.455 & & 39.026 & 690 & & 246 & 936 & 39.962 & $2.34 \%$ \\
\hline 1954 & 29.943 & 1.918 & & 40.234 & 747 & 4 & 205 & 956 & 41.190 & $2.32 \%$ \\
\hline 1955 & 18.486 & 1.328 & & 28.690 & 1.336 & & 121 & 1.457 & 30.147 & $4.83 \%$ \\
\hline 1956 & 16.814 & 1.503 & 1.612 & 26.072 & 1.851 & 6 & 167 & 2.024 & 28.096 & $7.20 \%$ \\
\hline 1957 & 19.931 & 1.628 & 4.158 & 32.150 & 4.640 & 5 & 99 & 4.744 & 36.894 & $12.86 \%$ \\
\hline 1958 & 19.829 & 1.596 & 1.619 & 29.207 & 6.264 & 2 & 127 & 6.393 & 35.600 & $17.96 \%$ \\
\hline 1959 & 16.400 & 4.569 & 3.961 & 29.780 & 4.838 & 6 & 130 & 4.974 & 34.754 & $14.31 \%$ \\
\hline 1960 & 12.451 & 5.679 & 4.895 & 28.513 & 6.434 & 54 & 158 & 6.646 & 35.159 & $18.90 \%$ \\
\hline 1961 & 16.073 & 3.370 & 2.635 & 27.499 & 10.492 & 277 & 304 & 11.073 & 38.572 & $28.71 \%$ \\
\hline 1962 & 13.555 & 2.425 & 2.739 & 24.376 & 16.798 & 1.393 & 435 & 18.626 & 43.002 & $43.31 \%$ \\
\hline 1963 & 11.281 & 2.922 & 3.424 & 22.420 & 29.843 & 2.118 & 837 & 32.798 & 55.218 & $59.40 \%$ \\
\hline 1964 & 4.929 & 1.601 & 4.770 & 17.232 & 51.668 & 4.771 & 1.905 & 58.344 & 75.576 & $77.20 \%$ \\
\hline 1965 & 3.051 & 1.852 & 5.197 & 17.557 & 60.267 & 12.197 & 1.467 & 73.931 & 91.488 & $80.81 \%$ \\
\hline 1966 & 2.607 & 13.357 & 6.795 & 33.266 & 63.611 & 11.250 & 3.868 & 78.729 & 111.995 & $70.30 \%$ \\
\hline 1967 & 3.271 & 11.516 & 6.615 & 28.584 & 59.597 & 4.070 & 2.461 & 66.128 & 94.712 & 69.82\% \\
\hline 1968 & 3.512 & 10.841 & 6.833 & 27.014 & 58.741 & 8.435 & 2.037 & 69.213 & 96.227 & 71.93\% \\
\hline 1969 & 2.537 & 13.111 & 6.502 & 27.383 & 110.614 & 15.406 & 2.269 & 128.289 & 115.672 & $82.41 \%$ \\
\hline 1970 & 1.669 & 9.726 & 6.529 & 22.659 & 135.667 & 22.915 & 1.964 & 160.546 & 183.205 & 87.63\% \\
\hline 1971 & 1.200 & 8.839 & 6.983 & 21.962 & 110.820 & 24.273 & 1.418 & 136.511 & 158.473 & $86.14 \%$ \\
\hline 1972 & 1.158 & 7.574 & 6.845 & 20.122 & 68.692 & 24.946 & 1.785 & 95.423 & 115.545 & $82.59 \%$ \\
\hline 1973 & 890 & 8.160 & 7.403 & 22.091 & 63.942 & 38.444 & 5.255 & $\mid$\begin{tabular}{|l|l|}
$\mid$ & 07.641
\end{tabular} & 129732 & 82.97\% \\
\hline 1974 & 729 & 9.540 & 11.650 & 25.822 & 37.727 & 13.352 & 3.958 & 55037 & 80859 & $\mid 68.07 \%$ \\
\hline
\end{tabular}

Quadro 1.

Emigração Portuguesa por destinos 1950-1974.

Fonte: Adaptado de Baganha, 1994.

Após o período de relativa estagnação que se seguiu à crise económica de 1973 e à revolução de 25 de Abril de 1974, a mobilidade externa da população portuguesa conheceu um ressurgimento a partir de meados dos anos 80 que se intensificou durante as décadas posteriores em ciclos sucessivos de retração e expansão (Marques e Góis, 2013).

Neste novo período de expansão dos anos 80 já serão outros os destinos prevalecentes, designadamente a Suíça, a Alemanha (sobretudo após 1989) e o Luxemburgo. Os dados apresentados no quadro seguinte sintetizam a evolução da emigração portuguesa para destinos selecionados da Europa a partir de 1990. É possível notar que, em termos 
agregados, a entrada de portugueses regista durante a segunda metade da década de 1990 uma diminuição face ao quinquénio anterior, influenciada, sobretudo, pela desaceleração económica verificada em alguns dos principais destinos da emigração portuguesa (em particular na Suíça). Este período de retração prolonga-se, com diferentes intensidades e com diferentes ritmos de recuperação até ao início do século XXI. As saídas permanentes de emigrantes para países como a França ou Suíça das décadas anteriores foram-se permutando em saídas de temporalidades mais curtas, circulares ou consecutivas para um maior conjunto de países (Peixoto et al., 2019). A partir do ano 2000, a evolução é genericamente positiva e com uma nova fase de intensificação da emigração após a primeira década do século XXI.

\begin{tabular}{|c|c|c|c|c|c|}
\hline Alemanha & $98561 \mid$ & 102914 & 34657 & 29074 & 50692 \\
\hline Espanha & & 7394 & 34598 & 82110 & 31488 \\
\hline Luxemburgo & 16924 & 10181 & 16220 & 20401 & 22117 \\
\hline Reino Unido & & 5286 & 50474 & 59030 & 129761 \\
\hline Suiça & 95656 & 28095 & 52244 & 72235 & 81406 \\
\hline França & 17566 & 31965 & 21128 & - & 36850 \\
\hline Bélgica & 11717 & 7436 & 8578 & 13042 & 17742 \\
\hline Total & 240424 & 193271 & 217899 & 275892 & 370056 \\
\hline
\end{tabular}

\section{Quadro 2.}

Evolução da emigração para países Europeus selecionados (1990-2015)

Góis e Marques, 2018.

Resumindo. Quando analisamos as principais alterações dos fluxos migratórios ao longo das últimas décadas são várias as características que se destacam. Em primeiro lugar, desde há muito que a emigração portuguesa é, sobretudo, uma emigração laboral que busca em destinos bem definidos um alargamento do mercado de trabalho português, onde os rendimentos são baixos e a estrutura de carreiras é muito deficiente. Em segundo lugar, atualmente, e, diferentemente do verificado noutros períodos emigratórios, caracterizados pela existência de um país de destino dominante em cada um dos períodos (que marcaram inclusive a sua denominação: o "ciclo brasileiro", o "ciclo francês"), a emigração 
portuguesa que se desenvolve a partir do ano 2000 apresenta uma geografia de destinos mais diversificada (Malheiros, Marques e Góis, 2016). Em terceiro lugar, sobretudo a partir de 2005, a emigração para os países da Europa Central e do Norte (responsável por, sensivelmente, dois terços das saídas totais), é complementada por fluxos migratórios que se dirigem para o hemisfério Sul para países como Angola, Brasil ou Moçambique. A emigração portuguesa para estes destinos assinala uma modificação na posição de Portugal no designado sistema migratório lusófono (Baganha, 2009; Góis e Marques, 2009; Peixoto, 2004) e em geral, um reposicionamento no sistema migratório europeu (Góis e Marques, 2020) ou no sistema migratório global.

\section{De país de emigração a país de imigração e vice-versa}

A discussão e o equilíbrio entre a perenidade e temporalidade dos fluxos migratórios e a permanência de elevado número de portugueses no exterior é uma lição que a história nos tem ajudado a construir. Fernando Luís Machado (1999), por exemplo, afirmava no final dos anos 1990 que Portugal não devia ser visto como um país só de imigração uma vez que, numa escala muito mais reduzida e em moldes diferentes dos do passado, a emigração continuava a ter uma expressão não negligenciável (Machado, 1999). Félix Neto reforçava esta ideia afirmando que "Portugal é hoje (1993) simultaneamente um país de emigração e de imigração" (Neto, 1993). Outros autores afirmam que convém não esquecer que, do ponto de vista quantitativo, se bem que as estatísticas disponíveis relativamente aos fluxos migratórios nem sempre deem conta da realidade, Portugal tem muito mais emigrantes que imigrantes e, neste sentido, continua a ser um país de emigração (Rocha-Trindade, 2000). A transição em curso, de "país de emigração" para "país de imigração" é, no que respeita à imigração, o resultado cumulativo de: i) repatriamento dos portugueses residentes nas ex-colónias e uma migração de refugiados da guerra colonial em meados dos anos 70 ; ii) diferentes ciclos e tipos de imigração (trabalhadores, reagrupamento familiar e de inativos (estudantes ou reformados) sobretudo a partir de final dos anos 80 . Por muito que a imigração tenha contribuído para um reposicionamento de Portugal no sistema migratório global, a estruturalidade da emigração foi sempre mais forte revelando um posicionamento semiperiférico da sociedade e economia portuguesas (Góis e Marques, 2009). Este debate faz hoje parte da sociedade portuguesa e os seus ecos encontram-se bem presentes na estrutura da governação política destes fenómenos. 
Deixando de ser países de emigração, Espanha, Itália, Grécia e Portugal passam a integrar a Europa da imigração, formando uma "nova porta de entrada", transposta por imigrantes africanos, sul-americanos, do médio oriente e asiáticos, que tanto podem procurar fixar-se no país de chegada, como usá-lo enquanto passagem para outros destinos (Peixoto et al., 2016). Por outro lado, a geografia das origens da imigração é também de destacar. O facto de três países da Europa do Sul (Itália, Espanha e Portugal), não sendo clássicos recetores de imigrantes, aparecerem entre os quatro primeiros lugares da lista dos países com maior número de imigrantes do hemisfério sul é um dado revelador das mudanças em curso no sistema migratório europeu (Machado, 1997, p. 37) e do novo posicionamento estratégico destes países no sistema migratório global.

O facto de a imigração laboral em Portugal se cingir até final dos anos 1990 quase só aos países lusófonos sugeria que o país ocupava então, não um lugar de primeira linha nas rotas migratórias que se dirigem à União Europeia como um todo, mas um nicho que só era procurado pelos imigrantes dos palop e do Brasil e relativamente ao qual não se revelava atrativo para outros imigrantes. A imigração portuguesa parecia assim ter um carácter quase "doméstico" ou "caseiro", tudo se passando entre uma mesma família internacional de países (Machado, 1997, p. 39). A partir dos anos 2000, Portugal integra-se por inteiro no sistema global das migrações e vai competir pelos trabalhadores migrantes como qualquer outro país. A sua posição semiperiférica assume, deste modo, novos contornos, não abandonando a lógica de plataforma redistributiva ou de destino final para os migrantes dos países com os quais detinha relações coloniais (ex. PALOP ou Brasil), torna-se destino de atração para migrantes fora da sua lógica tradicional de influência (ex. imigrantes da Europa de Leste) e vê, deste modo, crescer quer o volume total de imigrantes quer o número de nacionalidades que compõem a imigração em Portugal. Muitos destes migrantes escolhem Portugal como porta de entrada na EU, outros, porém, escolhem Portugal como destino final porque conjunturalmente é o que melhor corresponde às suas expectativas (ex. existência de trabalho, possibilidade de legalização, facilidade de permanecer ilegal, etc.). 


\section{Evolução recente da população estrangeira em Portugal}

Os dados do X Recenseamento Geral da População realizado em 1960 indicam que em 1960 residiam no país 29.579 cidadãos de nacionalidade estrangeira, sendo a maioria destes de origem Europeia (67\%) e cerca de $40 \%$ espanhóis (sobretudo galegos). Dos restantes estrangeiros, 22\% eram de nacionalidade brasileira e, somente, 1,5\% provinham de um país africano (Esteves, 1991, p. 161). A revolução de 25 de Abril de 1974 que pôs fim à ditadura, os subsequentes processos de descolonização e a independência dos atuais países africanos de língua portuguesa marcaram uma alteração profunda dos movimentos migratórios com destino a Portugal, assistindo-se ao regresso de centenas de milhar de cidadãos daqueles territórios, originários da então metrópole e dos seus descendentes ali nascidos (Pires, 1984).

Entre 1975 e 1980 a população estrangeira passou de 32.000 para 58.000, passando a ser constituída maioritariamente por cidadãos de origem africana (48\%), grande parte dos quais (98\%) provenientes das antigas colónias ultramarinas portuguesas em África (Angola, Cabo Verde, Guiné-Bissau, Moçambique e São Tomé e Príncipe). O número de estrangeiros a residir em território nacional correspondia, em 1981, a apenas 0,6\% do total da população residente (Baganha e Góis, 1998/1999).

Durante os anos 80 nota-se um novo aumento significativo na população estrangeira a residir em Portugal, ultrapassando, no final da década, pela primeira vez a centena de milhar (ou $1 \%$ da população). $O$ aumento da população estrangeira tornou-se ainda mais intenso no decurso dos anos 90 em que a proporção de estrangeiros na população total passou de 1,1\%, em 1990, para 1,9\%, em 1999. Esta evolução foi particularmente sentida entre a população proveniente do continente africano e do continente europeu que, em 1999 , representavam $76,6 \%$ do total de imigrantes presentes em território nacional. O somatório de todos os imigrantes provenientes de um país de língua portuguesa mostra que este grupo de países representava, em 1999, aproximadamente 55\% da população estrangeira a residir legalmente em Portugal, o que constituía um importante indicador do significado do passado colonial português e da manutenção de contactos sociais e culturais entre estes países e Portugal na constituição e consolidação deste fluxo migratório (Baganha e Góis, 1998/1999). 


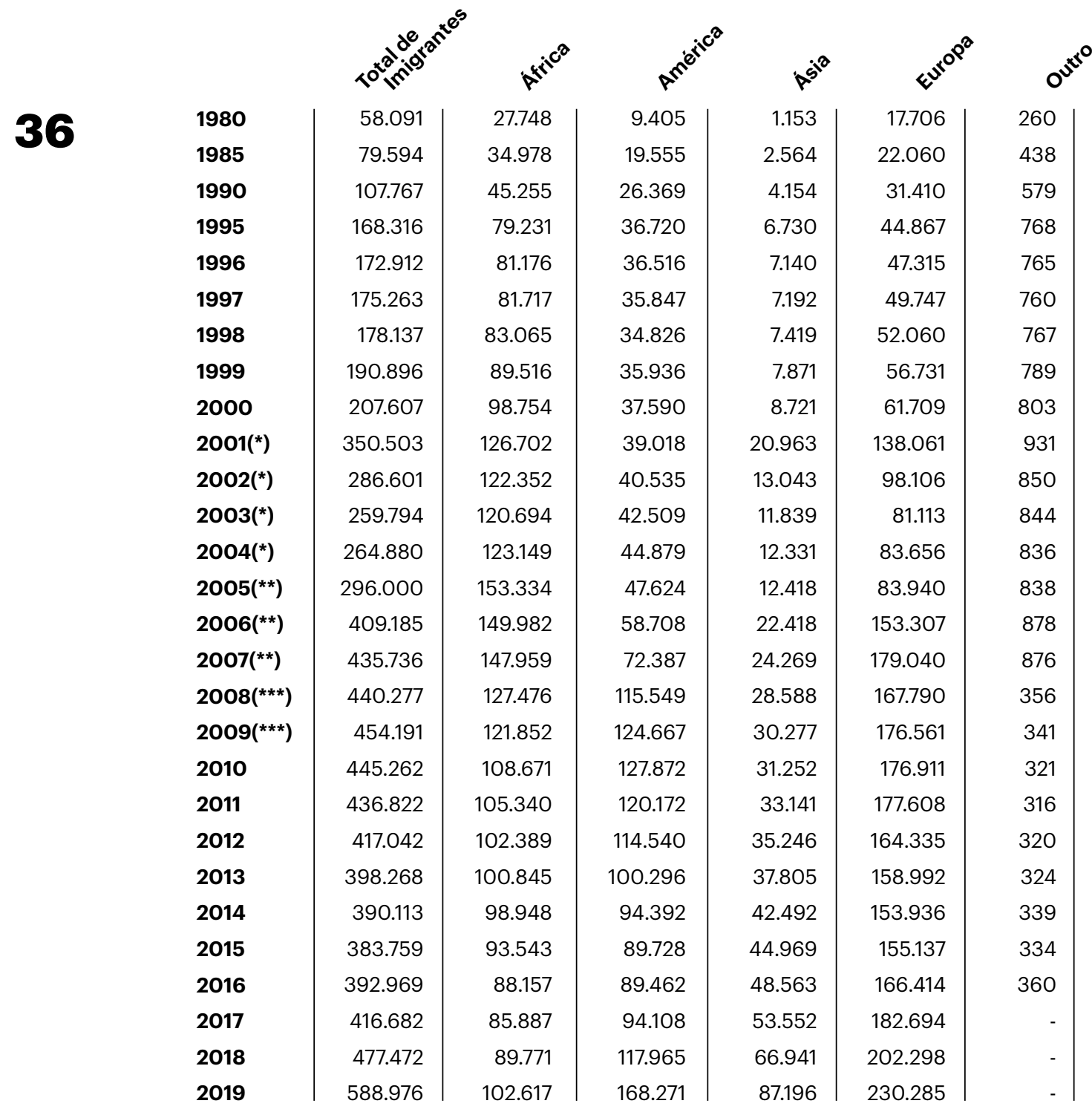

\section{Quadro 3.}

População estrangeira em Portugal por Continente de Origem, 1980-2019

Fonte: 1980-1995: INE, Estatísticas Demográficas e SEF, Estatísticas, cit. in Baganha, 1996 1996-2001: INE, Estatísticas Demográficas, 1996-2001 2001-2012: SEF, Estatísticas [http://sefstat.sef.pt/relatorios.aspx] 2013-2016: INE, INE, População estrangeira com estatuto legal de residente

2017-2019: INE | SEF/MAI - População

Estrangeira com Estatuto Legal de Residente via PORDATA

Notas:

(*) Inclui Autorizações de Residência e Autorizações de Permanência (**) Inclui Autorizações de Residência, Prorrogações de Autorizações de Permanência e Prorrogações de Vistos de Longa Duração (***) Inclui Autorizações de Residência e Prorrogações de Vistos de Longa Duração 
Como revela o quadro anterior, o stock da população estrangeira em Portugal cresceu ininterruptamente desde 1980 até 2001, ainda que, com ritmos de crescimento diferentes ao longo deste período. De facto, depois de um intenso crescimento na segunda metade dos anos 70, (a taxa anual média de crescimento foi de $11,9 \%$ entre 1975 e $1981^{1}$ o ritmo de crescimento da fixação de estrangeiros abranda durante a década de 80 , e acelera novamente nos anos 90 . Apesar do crescimento da população estrangeira ser constante durante

1 Estatísticas Demográficas, INE,1995. 2 S Serviço de Estrangeiros e Fronteiras (SEF) (1999); Baganha e Marques (2001) e Serviço de Estrangeiros e Fronteiras (SEF) (Estatísticas de 2000). os anos 80 e 90, em 2000 o número de estrangeiros com residência legal era ainda de pouco mais de 200 mil pessoas, ou seja aproximadamente $2 \%$ da população do país. ${ }^{2}$ Acresce que, na viragem para o século $X X I$, a imigração de países terceiros para Portugal era maioritariamente (76\% em 1999 e 77\% em 2000) constituída de imigrantes de países lusófonos, isto é, das ex-colónias portuguesas em África e do Brasil. A percentagem restante encontrava-se dispersa por mais de cem nacionalidades, nenhuma das quais apresentava valores numéricos muito significativos (Serviço de Estrangeiros e Fronteiras (SEF), Estatísticas de 1999, Estatísticas de 2000). Apesar de um crescimento contínuo ao longo de 21 anos (1980-2001), a presença de imigrantes em Portugal era, até 2001, relativamente fraca e a maioria dos movimentos que ocorriam podiam atribuir-se diretamente ao passado colonial, a relações históricas e culturais bem como a relações económicas.

Com o novo milénio chegaram migrantes inesperados alterando toda a dinâmica imigratória no país e as políticas migratórias portuguesas (Góis e Marques, 2016). A emigração do Leste europeu para Portugal começou em 2000. Tendo em conta os padrões migratórios dos anos 80 e dos anos 90 esta mudança foi súbita e inesperada. Por ter sido, simultaneamente, repentino e intenso, transformou a composição e o panorama nacional da população imigrante (Baganha, Marques e Góis, 2004). Até esta época não existiam laços históricos, culturais ou económicos privilegiados dos países da Europa de Leste a que se pudessem atribuir o súbito e intenso movimento de imigrantes da Europa de Leste para Portugal.

O ano 2000 marca o início de um processo de transformação das origens geográficas dos imigrantes que começam a provir maioritariamente da Europa do Leste, em especial da Ucrânia, e de um aumento significativo da imigração com origem no Brasil que daria origem a sucessivas vagas migratórias (Peixoto, Padilla, Marques e Góis, 2015). Elementos distintivos deste fluxo, em particular do de origem Leste Europeia, são a sua forte intensidade e a sua concentração num período temporal relativamente 
curto (2 a 3 anos, entre 2000 e 2002) com uma progressiva retração da vaga migratória e a permanência em Portugal de um número assinalável de imigrantes com esta origem. Trata-se de um fluxo que só se tornou estatisticamente importante após a concessão, ao abrigo do artigo 55. ${ }^{\circ}$ do Decreto-Lei n. ${ }^{\circ}$ 4/2001 de 10 de Janeiro, de 126.901 autorizações de permanência a trabalhadores imigrantes que se encontravam ilegalmente no país. Em 2003, os imigrantes provenientes da Ucrânia passam a constituir o grupo mais numeroso, seguido pelos brasileiros e pelos cabo-verdianos. Em conjunto estas três nacionalidades representavam nesse ano $52,6 \%$ do total de imigrantes de países terceiros a residir legalmente em Portugal.

A preponderância destes três grupos nacionais no total da população estrangeira a residir legalmente em Portugal manteve-se até ao presente, alterando-se, somente, a importância relativa de cada uma das nacionalidades que foi oscilando ao longo da última década e meia. Assim, em 2016 , os imigrantes brasileiros representavam $20,4 \%$, os cabo-verdianos $9,2 \%$ e os ucranianos $10,6 \%$ e do total de 397.731 imigrantes com residência legal em Portugal. Já em 2019, os ucranianos tinham passado para a quinta posição (5\%) com os imigrantes com origem no Brasil $(25,6 \%)$, Cabo Verde (6,3\%), Reino Unido (5,8\%) e Roménia (5,3\%) a ocuparem as quatro primeiras posições (Góis e Marques, 2018). Ressalve-se porém o facto de, em muitos casos esta diminuição (ex. do número de ucranianos ou de cabo-verdianos) não corresponder a um retorno aos países de origem respetivos mas a uma diminuição estatística por via da aquisição de nacionalidade portuguesa a que se segue, num número indeterminado de casos, uma re-emigração para outros países europeus (Góis e Marques, 2018).

\section{Conclusão}

Atualmente, em resultado de diversos fluxos imigratórios, a composição nacional dos estrangeiros a residir em Portugal é mais diversificada do que durante as décadas anteriores. Integra atualmente, para além de uma proporção significativa de imigrantes das ex-colónias portuguesas, cidadãos da União Europeia ou imigrantes provenientes do Brasil. O número de estrangeiros residentes aumentou ao longo de 21 anos 1980-2001, voltou a aumentar entre 2003 e 2009 ano em que atingiu o seu máximo de sempre. Desde então o número de imigrantes em Portugal reduziu-se continuamente até 2015 ano em que retomou uma trajetória ascendente com um novo máximo em 2019 (588.976 imigrantes legalmente residentes) (SEF, 2020). Este número continuou a subir nos 
primeiros meses de 2020, mas tem, devido aos efeitos da pandemia Covid-19, uma previsão de decréscimo para os tempos mais próximos.

A este grupo de estrangeiros a residir em Portugal há a acrescentar o conjunto de indivíduos que, por diferentes razões, não constam, ou deixaram de constar, das estatísticas portuguesas relativas à população estrangeira. Referimo-nos aos imigrantes que adquiriram nas últimas décadas a nacionalidade portuguesa em resultado de um processo de naturalização, aos descendentes de imigrantes nascidos em território nacional que podem (ou não) deter a nacionalidade portuguesa e, por último, os cidadãos portugueses em que pelo menos um dos seus progenitores tenha nascido fora do território nacional (ex. em Macau, Angola, Moçambique ou Goa).

No período de 39 anos, entre a primeira Lei de Estrangeiros (1981) e a atualidade, ocorreu uma mudança significativa na paisagem imigratória nacional, indiciando, por um lado, uma aceleração e diversificação dos ciclos imigratórios e, por outro, um processo de heterogeneização da população estrangeira residente em várias das suas características principais. Em resultado de diversos fluxos imigratórios, a composição nacional dos estrangeiros a residir em Portugal é atualmente mais diversificada do que foi durante as décadas anteriores.

Por seu turno, a emigração continua bem presente na demografia portuguesa. Os destinos migratórios alteraram-se e diversificaram-se sendo hoje predominantemente destinos europeus embora com a presença de importantes destinos fora da Europa. A dinâmica migratória não demonstra ainda tendências bem definidas com o saldo migratório (diferença entre o número de imigrantes e de emigrantes) a ser de novo positivo após quase uma década em que foi negativo. Com o dealbar de uma nova crise económica em Portugal e o ressurgimento do desemprego em massa a válvula estrutural que é a emigração tende a reemergir e o país será menos atrativo para a imigração. A paisagem humana em Portugal altera-se com as migrações e delas depende num país que envelhece ao sabor de um tempo em que nascem menos crianças e a esperança média de vida vai evoluindo positivamente. Não seríamos o que somos hoje sem as migrações, não seríamos nós sem os outros. 


\section{Bibliografia}

Antunes, M. L. M. (1970). "Vinte anos de emigração portuguesa: alguns comentários". Análise Social, 8 (30-31), 299-385.

- (1973). A emigração portuguesa desde 1950: dados e comentários. Lisboa: Universidade Técnica de Lisboa. Instituto Superior de Economia. Gabinete de Investigações Sociais.

Baganha, M. (1991). "Uma Imagem Desfocada - a emigração portuguesa e as fontes sobre a emigração". Paper presented at the Análise Social.

- (1992). Principais Características e Tendências da Emigração Portuguesa. Paper presented at the Actas do $2^{\circ}$ Congresso Português de Sociologia.

- (2009). "The Lusophone Migratory System: Patterns and Trends". International Migration, 47(3), pp. 5-20.

Baganha, M., Marques, J. C. e Góis, P. (2010). Imigração Ucraniana em Portugal e no Sul da Europa: a emergência de uma ou várias comunidades? Lisboa: ACIDI IP.

Baganha, M. e Góis, P. (1998/1999). "Migrações internacionais de e para Portugal: o que sabemos e para onde vamos?" Revista Crítica de Ciências Sociais, 52/53, 229-280.

Baganha, M. e Marques, J. (2001). Imigração e Política: O caso Português. Lisboa: Fundação Luso-Americana.

Baganha, M. I., Marques, J. C., Góis, P. (2004). "Novas migrações, novos desafios: A imigração do Leste Europeu". Revista Crítica de Ciências Sociais (69), pp. 95-115.

- (2004). "The unforeseen wave: migration from Eastern Europe to Portugal". In M. I. Baganha \& M. L. Fonseca (Eds.), New Waves: Migration from Eastern to Southern Europe (pp. 23-39). Lisboa: Luso-American Foundation.

- (2004). "Novas migrações, novos desafios: A imigração do Leste Europeu". Revista Crítica de Ciências Sociais, 69, pp. 95-115.

Baganha, M., Marques, J. C. e Fonseca, G. (2000). Is an Ethclass Emerging in Europe? The Portuguese Case. Lisboa: Luso American Development Foundation.
Baganha, M. e Peixoto, J. (1996). "O Estudo das Migrações Nacionais: Ponto de Intersecção Disciplinar". In J. M. Carvalho Ferreira, R. Marques, J. Peixoto e R. Raposo (Ed.), Entre a Economia e a Sociologia (pp. 233-239). Oeiras: Celta.

Castles, S. (2005). Globalização, Transnacionalismo e Novos Fluxos Migratórios. Lisboa: Fim de Século.

de Haas, H., Czaika, M., Flahaux, M.-L., Mahendra, E., Natter, K., Vezzoli, S., \& Villares-Varela, M. (2019). "International Migration: Trends, Determinants, and Policy Effects". Population and Development Review, 45(4), 885-922. doi:10.1111/padr.12291

Devoto, F., e González-Bernaldo, P. (2001). Emigration politique : une perspective comparative: Italiens et Espagnols en Argentine et en France, XIXe-XXe siècles. Paris: Harmattan.

Esteves, M. C. (1991). Portugal: País de Imigração. Lisboa: Instituto de Estudos para o Desenvolvimento.

Ferreira, J.-P., Lahr, M., Ramos, P. e Castro, E. (2020). "Accounting for global migrant remittances flows". Economic Systems Research, 32(3), 301-317. doi:10.1080/095353 14.2019.1659756

Góis, P. e Marques, J. C. (2009). "Portugal as a semiperipheral country in the global migration system". International Migration, $47(3), 19-50$.

- (2016). "A emigração portuguesa e o sistema migratório lusófono : complexidade e dinâmicas de um país de migrações" In: Observatorio Iberoamericano sobre Movilidad Humana, Migraciones y Desarrollo <http://hdl.handle.net/10400.8/1759>.

- (2018). Retrato de um Portugal migrante: a evolução da emigração, da imigração e do seu estudo nos últimos 40 anos. Coimbra, CES.

- (2020). "Portuguese intra-EU migration. The dynamics of an ongoing migration process". Racial and Ethnic Studies, (no prelo).

Guibentif, P. (1996). "Le Portugal face à l'immigration". Revue Européenne des Migrations Internationales, 12 (1), 121-139. 
Haas, H. d., Miller, M. J., e Castles, S. (2020). The age of migration : international population movements in the modern world (Sixth edition / ed., pp. 1 online resource (1 volume)).

King, R. (1995). Mass migration in Europe: the legacy and the future. Chichester: Wiley.

Machado, F. L. (1999). "Aspects et spécificités de l'immigration au Portugal". Migrances, 15, 82-93.

Malheiros, J., Marques, J. C., e Góis, P. (2016). "Geografias, processos migratórios e dinâmicas sociográficas da emigração contemporânea portuguesa: respondendo a algumas questões...". In J. Peixoto, I. T. d. Oliveira, J. Azevedo, J. C. Marques, P. Góis, J. Malheiros, \& P. M. Madeira (Eds.), Regresso ao Futuro: A nova Emigração e a Sociedade Portuguesa (pp. 273-296). Lisboa: Gradiva.

Marques, J. C., e Góis, P. (2012). "A evolução do sistema migratório lusófono. Uma análise a partir da imigração e emigração portuguesa". Revista Internacional em Língua Portuguesa, 24, pp. 213-232.

- (2013). "Dinâmicas do sistema migratório lusófono: um olhar a partir das migrações portuguesas". In L. Fonseca, P. Góis, J. C. Marques, \& J. Peixoto (Eds.), Migrações na Europa e em Portugal. Ensaios de homenagem a Maria loannis Baganha (pp. 185-203). Coimbra: Almedina.

Mateus, A. (2013). 25 anos de Portugal europeu: a economia, a sociedade e os fundos estruturais. Lisboa: Fundação Francisco Manuel dos Santos.
Neto, F. (1993). Psicologia da migração portuguesa. Lisboa: Universidade Aberta.

Peixoto, J. (2004). "Dinâmicas e regimes migratórios: o caso das migrações internacionais em Portugal". Análise Social, XLII(183), 445-469.

Peixoto, J., Candeias, P., Ferreira, B., Tiago de Oliveira, I., Azevedo, J., Marques, J. C. e Santana, E. (2019). "New Emigration and Portuguese Society: Transnationalism and Return" In: Springer \%U http://hdl.handle. net/10451/39031.

Peixoto, J., Padilla, B., Marques, J. C., e Góis, P. (2015). Vagas Atlânticas. Migrações entre Brasil e Portugal no Início do Século $X X I$. Lisboa: Mundos Sociais.

Pires, R. P. (1984). Os Retornados: um estudo sociográfico. Lisboa: Instituto de Estudos para o Desenvolvimento.

Rocha-Trindade, M. B. (2000). "História da Imigração em Portugal". Janus 2001 . Anuário de Relações Exteriores, Público/ UAL, 170-173.

Serviço de Estrangeiros e Fronteiras (SEF). RIFA, vários anos, Lisboa, SEF.

Silva, J. R. (2006). O investimento directo estrangeiro. In A. Romão (Ed.), A Economia Portuguesa - 20 Anos Após a Adesão (pp. 491-518). Coimbra: Almedina. 